\title{
ACESSO TECNOLÓGICO DE ALUNOS EM TEMPO DE PANDEMIA: DESAFIOS DO ENSINO APRENDIZAGEM DA MATEMÁTICA EM SÃO FELIX DO XINGU-PA
}

Pierre Pereira

\section{RESUMO}

Os alunos da cidade de São Félix do Xingu lutam para ter acesso às aulas de matemática durante a pandemia. Este estudo tem como objetivo analisar o ensino de matemática nas escolas da cidade de São Félix do XinguPA, durante a pandemia de Coidv19. Evidenciar a atenção da classe política, classe educadora e de estudiosos, para a democratização de serviços de tecnologia como instrumento para a educação, evidenciar o alto grau de disparidade das classes, quando o assunto é acesso tecnológico. Evidenciar a não democratização do acesso à Tecnologia de Informação e ComunicaçãoTIC, antes e durante a pandemia de COVID-19. Para evidenciar os desafios e dificuldades que alunos e professores têm de ultrapassar para que o processo de ensino e aprendizagem corra bem, em tempos de isolamento social, as escolas não podem continuar a funcionar. os professores precisam se renovar profissionalmente para que o ensino a distância continue e os alunos se mantenham atentos, interessados e motivados. Rememorar de forma sucinta sobre a história da matemática, a contribuição de personagens marcantes e 0 seu ensino até a idade contemporânea. Analisar se através dos tempos até o momento pandêmico as metodologias de ensino da matemática aplicadas pelos professores em sala de aula e de forma remota estão contribuindo para desenvolver uma aprendizagem contextualizada. Pesquisa qualitativa, de caráter exploratório, e baseia-se em consultas bibliográficas, análises de Artigos, acessos a e-books e sites de internet pertencentes a Órgãos públicos, sites voltados para a educação. Os resultados apontam que buscou-se ofertar o ensino por mediação tecnológica durante o isolamento social, tendo em vista evitar evasão escolar e proliferação da doença. Entretanto, vários fatores interferem diretamente nesse processo, e impedem que o ensino e a aprendizagem sejam de qualidade. Diante de tudo o que foi exposto evidenciase que as medidas sugeridas para suprirem a ausência das aulas presenciais e o cumprimento com o dever de educar não é abrangente, tanto pela falta de aparelhos, como pela falta de conhecimento mostrada por alunos como 
também por professores. O que foi assunto de discussão entre alunos, professores, responsáveis e equipe pedagógica, ocasionando divergência entre as opiniões e assim, servindo como instrumento de busca para melhorias no ensino de tal disciplina. Entre as principais dificuldades constatadas está o status de "difícil" com o qual a disciplina de Matemática foi titulada, fatores genéticos e biológicos que interferem diretamente na capacidade de aprendizado do indivíduo e a insuficiente formação do professor. Em contrapartida, as aulas dinâmicas e o uso da tecnologia são os fatores que mais tem atraído os alunos e os feito pensar, trazendo resultados mais satisfatórios. Durante o período de isolamento social em que as escolas foram desautorizadas a continuar as atividades presenciais. E nesse contexto da pandemia, os professores de Matemática utilizaram de diversos recursos para que as aulas remotas mantivessem a qualidade das presenciais.

\section{CAPÍTULO I - ENSINAR MATEMÁTICA POR MEIO DE AULAS REMOTAS COM POUCO ACESSO TECNOLÓGICO PELOS ALUNOS}

Por ser um sistema que oferece reciprocidade de conhecimentos entre professores e alunos, o processo ensino-aprendizagem é baseado no conteúdo do que o aluno aprende. ser ensinado no ambiente de estudo e se for consistente com o que foi aprendido.

Como argumenta Brandão (1988), a educação faz parte de todo aquele que aprendeu a utilizá-la, como qualquer outro grupo, independentemente do clima.

Brandão (1988) afirma uma duplicidade do ensino grego, com complicações que, embora novas, o ensino atual tem sido capaz de resolver., ou seja, o uso da técnica. Segundo os parâmetros da educação grega, a obra de arte mais perfeita era representada pelo ser humano adquirindo conhecimento. Para os gregos, a educação era responsável pelos conhecimentos transmitidos, bem como pelas interações interpessoais. Paidéia, que em grego significa "formação integral", nasceu para que a educação fosse tal que o ser humano pudesse viver em sociedade, em 
ambientes chamados de galpões educacionais. O legislador Sólon fala sobre o processo educativo.

As crianças devem, antes de tudo, aprender a nadar a ler; em seguida, os pobres devem exercitar-se na agricultura ou em uma indústria qualquer, ao passo que os ricos devem se preocupar com a música e a equitação, e entregar-se à filosofia, à caça e à frequência aos ginásios (SÓLON apud BRANDÃO, 1984, pg. 37).

Brandão (1988) sugere que uma forma diferente de absorver o que é a educação e seu processo de ensino-aprendizagem é tentar entender o que é exposto por todos que a fazem., Como legisladores, professores, educadores, educadores e alunos. Um dos mais tradicionais dicionários brasileiros a define como:

Ação e efeito de educar, de desenvolver as faculdades físicas, intelectuais e morais da criança e, em geral, do ser humano; disciplinamento, instrução, ensino (dicionário contemporâneo da língua portuguesa, caldas avele, pg. 54).

Com a concepção de certos filósofos e educadores, a educação tem sido definida como meio de desenvolvimento e de amadurecimento. são formas de autoeducação, que surgem de práticas específicas e distintas de cada indivíduo: a educação nunca será observada como parte de um todo, mas observada, dentro dos limites das possibilidades de cada um. Educar pode ser pensado como uma tarefa de todos, mas o desenvolvimento de cada pessoa é único para cada pessoa, existem várias conjecturas sobre o que é educação.

Brandão (1988), diz que:

Educação. Do latim educare, que quer significa extrair, tirar, desenvolver. Consiste essencialmente na formação do homem de caráter. A educação é um processo vital, para o qual é um processo vital, para o qual concorrem forças naturais e espirituais, conjugadas pela ação consciente do educador e pela vontade livre do educando. Não pode, pois, ser confundida com o simples desenvolvimento ou crescimento dos seres vivos, nem com a mera adaptação do indivíduo ao meio. É atividade criadora, que visa a levar o ser humano a realizar as suas potencialidades físicas, morais, espiritual e intelectual. Não se reduz à preparação para fins exclusivamente utilitários, como uma profissão, nem para desenvolvimento de características parciais da personalidade, como um dom artístico, mas, abrange o homem integral, em todos os aspectos de seu corpo e de sua alma, ou seja, em toda a extensão de sua vida sensível, espiritual, intelectual, moral, individual, doméstica e social, para 
elevá-la regulá-la e aperfeiçoá-la. É processo continuo que começa nas origens do ser humano e se estende até a morte (BRANDÃO, 1988, p. 64,65).

Percebemos um desconforto profundo. com a formação do ser, essa descrição é bem conhecida na metodologia grega, ou seja, na Paideia, o objetivo era a formação integral do ser. A educação visa nortear o desenvolvimento do ser humano, visando a pessoa que se tornará, ao seu conhecimento, a capacitá-lo para viver em sociedade. Observamos que o processo de ensino-aprendizagem ocorre de diferentes maneiras. A função de educar para transformar os indivíduos para um mundo melhor continua sendo uma meta. O ser humano assimila o processo construtivo do conhecimento apenas a partir do momento em que começa a problematizar suas práticas. em que o ambiente escolar auxilia em seu processo de evolução.

O papel da escola não é apenas proporcionar aos alunos a aprendizagem da leitura e da escrita, mas também prepará-los para a interação, através da educação para mudar os rumos da sociedade, uma vez que o objetivo da escola é proporcionar e desenvolver a estudante. Em tudo.

Sabemos que o professor é o protagonista desse processo e que os alunos adquirem conhecimentos de diferentes formas e lugares. Cabe ao professor transmitir esse conhecimento ao aluno, arbitrar esse processo para que o aluno aprenda de forma objetiva, portanto é essencial que o professor seja preparado e apoiado pela escola. É fato que o processo de aprendizagem envolverá não só a escola, mas também a família, a troca recíproca entre professores e alunos, as interações entre outros fatores cuja funcionalidade é a epistemologia dos educadores.

Palangana (2015) comenta que:

$\mathrm{Na}$ filosofia kantiana, o processo de conhecimento guarda em si uma peculiar complexidade. Em poucas palavras, pode-se inferir que ele ocorre da seguinte maneira: as percepções sensitivas captam os dados empíricos de modo caótico e desorganizado; a intuição organiza esses dados, atribuindo-Ihes uma forma a priori, constituída em função das categorias de tempo e espaço. Já no nível do entendimento, esse conteúdo, que era pura intuição, é flexionado quanto a sua qualidade, quantidade, relações e modalidades, possibilitando assim a construção e a unidade do fenômeno. Além dessa unidade, dada pelo entendimento que se baseia sempre nas intuições, existe uma unidade total e definitiva pretendida pela razão, 
a qual, agindo sobre os conceitos do entendimento, possibilita a unidade das leis empíricas. (PALANGANA, 2015, P. 34).

O desenvolvimento da aprendizagem é realmente surpreendente, cada um aprende de forma diferente e é aí que entra em cena o papel do professor, do mediador, do conhecimento que entra em sala de aula.

Isso significa que o professor deve estabelecer um vínculo entre o que o aluno vai aprender e relacioná-lo com os conhecimentos que o aluno já possui, para que o aluno se interesse pelo que vai estudar e, assim, crie um vínculo com a sala de aula. e vida cotidiana. vida.

Para Piaget (apud Kamii 1990, p.17), o desenvolvimento e aprendizagem partem de dois princípios fundamentais: o sujeito que busca 0 conhecimento de um determinado jeito e o objeto a ser reconhecido pelo sujeito. Para ele, o conhecimento parte da organização e sistematização da informação; estruturar e explicar os fatos com base nas experiências vividas. $O$ conhecimento vem da exploração de um determinado assunto, ou seja, o objeto a ser estudado pelo aluno. Nesse sentido, o processo de compreensão do objeto será a essência do conhecimento produzido pelo aluno. Dessa forma, ele será capaz de organizar as informações, problematizar o que se confronta e, por meio da detecção de hipóteses, conhecer o assunto em questão.

Segundo Kamii (1990, p. 18)

O fato de que a abstração reflexiva não pode ocorrer independente das primeiras construções de relações feitas pelas crianças tem implicações importantes para o ensino do número. Este princípio implica que a criança deve colocar todos os tipos de conteúdo (objetos, eventos e ações) dentro de todos os tipos de relações para chegar a construir o número.

O entendimento sobre abstração empírica é importantíssimo nos primórdios da vida escolar. É o momento em a criança trás para a escola seu 0 conhecimento empírico e o educador tem a chance de observar e explorar tal conhecimento. Em um primeiro momento, tudo acontece através do processo de observação.

Para Piaget (1967), o desenvolvimento e a aprendizagem partem de dois princípios básicos: a disciplina busca o conhecimento de uma determinada disciplina e a disciplina é reconhecida pela disciplina. Para ele, o conhecimento 
vem da organização e sistematização das informações; estruturar e interpretar eventos com base nas experiências vividas. $O$ conhecimento surge a partir da descoberta de um determinado assunto, ou seja, o objeto de estudo dos alunos. Nesse sentido, o processo de compreensão do objeto será a essência do conhecimento gerado pelo aluno. Desta forma, saberá organizar as informações, determinar qual o problema a resolver e, formulando hipóteses, conhecer $\mathrm{o}$ assunto a resolver.

Os alunos devem desconsiderar o conhecimento das várias ações que realizam sobre si mesmos. Piaget chama isso de "abstração reflexiva ou construtiva". Para ele, aprender em sala de aula está diretamente ligado ao conhecimento, pois aprender é saber realizar determinada ação, e consciência é conhecer a ação realizada.

O problema do ensino são as práticas obsoletas dos professores, as mesmas técnicas utilizadas há anos, os professores não têm problematizado a forma de ensinar e "Acha-se muito, mas pesquisa-se pouco. Repete-se e copia-se quase tudo: de ideias a livros de hipóteses e teorias." (ZAGURY, 2006, p, 11-12).

Isso significa que os professores de hoje aprendem muito na teoria, mas na prática eles disponibilizam planos sem muito esforço, as ideias vêm de outras pessoas e a inovação é necessária.

Segundo Vygotsky (1998), a aprendizagem ocorre a partir de duas variáveis: o processo e o produto. $O$ processo é sobre o que o aluno já sabe e o produto é que o aluno já tem mais conteúdos ministrados pelo professor que eles transformam em novas noções.

Ainda segundo Vygotsky (1998), o aluno passa por dois tipos de desenvolvimento: o primeiro é o nível de desenvolvimento real ou emocional, que é a informação que a criança já possui em seu poder, trata dos problemas que a criança vivencia podendo resolver com a ajuda de pessoas mais experientes. irá defini-la como a zona de desenvolvimento proximal, que se refere a funções ainda não formadas pela criança. 